\title{
Carbon dots decorated graphitic carbon nitride as an efficient metal-free photocatalyst for phenol degradation
}

\author{
Hui Zhang, Lixia Zhao, Fanglan Geng, Liang-Hong Guo*, Bin Wan, Yu Yang \\ State Key Laboratory of Environmental Chemistry and Eco-toxicology, Research Centre for Eco- environmental Sciences, Chinese Academy of Sciences, 18 \\ Shuangqing Road, P.O. Box 2871, Beijing 100085, China
}

\section{A R T I C L E I N F O}

\section{Article history:}

Received 13 April 2015

Received in revised form 23 June 2015

Accepted 25 June 2015

Available online 17 July 2015

\section{Keywords:}

Carbon dot

Graphitic carbon nitride

Metal-free photocatalyst

Phenol

\begin{abstract}
A B S T R A C T
Environment-friendly metal-free photocatalysts represent a promising alternative to conventional metal-based semiconductors. In this report, a carbon dots (CDs) decorated graphitic carbon nitride $\left(\mathrm{g}-\mathrm{C}_{3} \mathrm{~N}_{4}\right.$ ) photocatalyst was synthesized via a facile impregnation-thermal method. Under visible light irradiation, a very low CDs content of $0.5 \mathrm{wt} \%$ in the $\mathrm{g}-\mathrm{C}_{3} \mathrm{~N}_{4} / \mathrm{CD}$ somposite resulted in a 3.7 times faster reaction rate for phenol photodegradation than pristine $g-C_{3} N_{4}$. Spectroscopic and photoelectrochemical characterizations revealed that impregnation of CDs into g- $C_{3} N_{4}$ not only enhanced the production of photogenerated electron-hole pairs by extending the visible light absorption region due to the upconverted photoluminescence character of CDs, but also facilitated electron-hole separation by band alignment in the $\mathrm{g}_{-} \mathrm{C}_{3} \mathrm{~N}_{4} / \mathrm{CDs}$ junction, thus yielded more holes, $\bullet^{\bullet} \mathrm{O}_{2}-$ and $\bullet \mathrm{OH}$ radicals to promote phenol degradation. These results highlight the potential application of sustainable metal-free photocatalysts in water purification.
\end{abstract}

(C) 2015 Elsevier B.V. All rights reserved.

\section{Introduction}

Sunlight-driven photocatalytic reactions represent a promising way to address the increasing environmental and energy concerns [1-4]. From the viewpoint of solar-energy use, photocatalytic performance strongly depends on the semiconductor's absorption capacity toward sunlight and the reaction efficiency of photogenerated charge carriers. To date, various visible-lightsensitive semiconductors, including multi-metal oxides, sulfides and oxynitrides, have been successfully fabricated by bandstructure engineering [5-8]. Nevertheless, considering the side issues such as scalability and sustainability, earth-abundant metalfree semiconductors are greatly desired. As a sustainable material, graphitic carbon nitride $\left(\mathrm{g}-\mathrm{C}_{3} \mathrm{~N}_{4}\right)$ represents an attractive visible light photocatalyst because of its suitable band gap $(2.7 \mathrm{eV})$ for sunlight absorption and outstanding catalytic activity [9]. The high chemical stability of $\mathrm{g}-\mathrm{C}_{3} \mathrm{~N}_{4}$ together with the low cost of mass production makes it an ideal candidate for applications like photocatalytic water splitting, $\mathrm{CO}_{2}$ reduction and pollutant degradation [10-14]. However, despite great progress in $\mathrm{g}-\mathrm{C}_{3} \mathrm{~N}_{4}$ synthesis, the weak van der Waals interactions between adjacent $\mathrm{CN}$ layers in

\footnotetext{
* Corresponding author.

E-mail address: LHGuo@rcees.ac.cn (L.-H. Guo).
}

g- $\mathrm{C}_{3} \mathrm{~N}_{4}$ impede charge transfer and separation, and thus impose severe limitations on the photocatalytic performance.

One promising strategy to enhance the photocatalytic performance of $\mathrm{g}-\mathrm{C}_{3} \mathrm{~N}_{4}$ is to form surface junctions to promote charge separation. Two typical approaches have been developed to construct effective surface junctions. One is to decorate $\mathrm{g}-\mathrm{C}_{3} \mathrm{~N}_{4}$ with metal nanoparticles (e.g., Au and $\mathrm{Ag}$ ) or carbon nanomaterials (e.g., carbon nanotube and graphene), which can effectively capture photogenerated electrons in $\mathrm{g}-\mathrm{C}_{3} \mathrm{~N}_{4}$ and improve catalytic efficiency [15-18]. The other promising approach is to construct semiconductor heterojunctions with a suitable band- alignment structure, such as $\mathrm{CdS}$ and $\mathrm{Cu}_{2} \mathrm{O}$ [19-23]. Such structures can simultaneously optimize light capture and facilitate charge separation at the interface between the two semiconductors. It is noted that the formation of effective junctions strongly depends on the crystal structure, band structure, electron affinity and interfacial contact of both materials. However, the main problem of these composites is the leaching of toxic metals during photocatalytic processes. Photocatalytic systems based on metal-free, sustainable materials are highly desirable for large-scale photocatalytic applications.

Recently, carbon dots (CDs), which are predominantly composed of graphitic carbon ( $\mathrm{sp}^{2}$ carbon) with a size below $10 \mathrm{~nm}$, have attracted considerable attention because of their unique optical and electronic properties [24,25]. The quantum effect endows CDs with broad-band optical absorption. Thus, CDs have been 

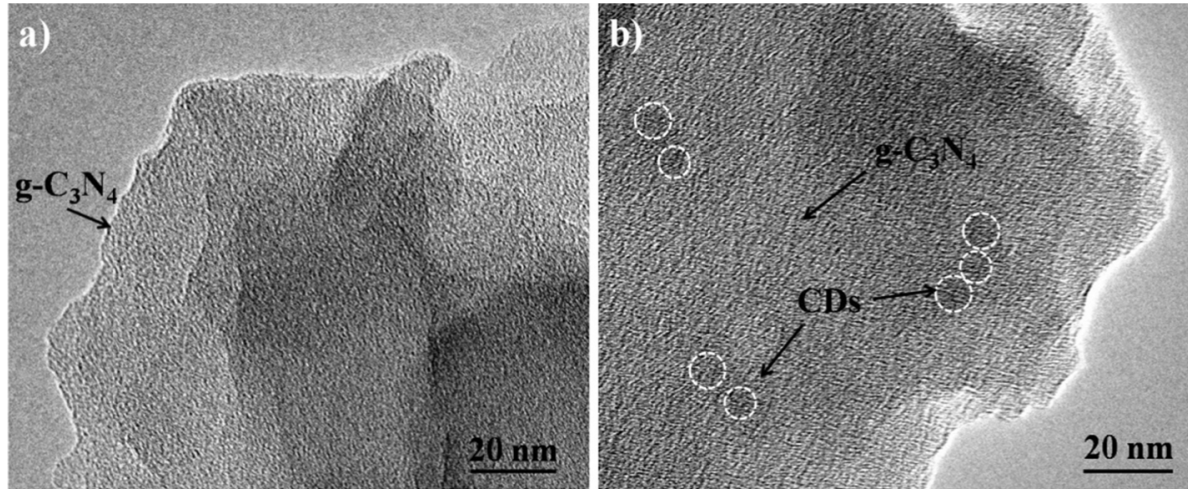

Fig. 1. TEM images of (a) $g-C_{3} N_{4}$ and (b) $g-C_{3} N_{4} / C D s(0.5 w t \%)$ composite.

widely used as light absorbers to couple with semiconductor nanoparticles, such as $\mathrm{TiO}_{2}, \mathrm{Si}$ and $\mathrm{Ag}_{3} \mathrm{PO}_{4}$, to improve their photocatalytic performance [26-28]. In addition, CDs also act as an electron acceptor or transporter to direct the flow of photogenerated charge carriers [29]. Considering the analogous $\pi$-conjugated structure of $\mathrm{g}-\mathrm{C}_{3} \mathrm{~N}_{4}$ and $\mathrm{CDs}$, the combination of these two materials is expected to deliver high photocatalytic performance.

With the above merits, we report an earth-abundant, metalfree $\mathrm{g}-\mathrm{C}_{3} \mathrm{~N}_{4} / \mathrm{CDs}$ heterojunction synthesized by directly coating CDs onto the $\mathrm{g}-\mathrm{C}_{3} \mathrm{~N}_{4}$ surface. The CDs decorated g- $\mathrm{C}_{3} \mathrm{~N}_{4}$ composite exhibited greatly enhanced photocatalytic activity toward phenol degradation under visible light irradiation compared with that of g- $\mathrm{C}_{3} \mathrm{~N}_{4}$. The role of the CDs in the composite was systemically investigated. The metal-free and environment-friendly properties of the g- $\mathrm{C}_{3} \mathrm{~N}_{4} / \mathrm{CDs}$ composite make it a promising photocatalytic system for practical applications.

\section{Experimental}

\subsection{Chemicals and materials}

Cyanamide was purchased from Alfa Aesar (Ward Hill, MA, USA). Phenol was purchased from Sigma- Aldrich (St. Louis, MO, USA). 5,5-Dimethyl-1-pyrroline-N-oxide (DMPO) was obtained from Dojindo Laboratories (Kumamoto, Japan). Methanol was obtained from Fisher Scientific (Pittsburgh, PA, USA). All other chemicals were of analytical grade and used without further purification. All solutions were freshly prepared with deionized water (resistivity: $18.2 \mathrm{M} \Omega$ ) obtained using a Millipore Milli-Q water purification system (Bedford, MA, USA).

\subsection{Synthesis of $g-C_{3} N_{4}$}

Pure $\mathrm{g}-\mathrm{C}_{3} \mathrm{~N}_{4}$ was prepared by a simple calcination method according to the literature [30]. Cyanamide was put into a quartz boat and heated in static air to $520^{\circ} \mathrm{C}$ (ramp rate: $2^{\circ} \mathrm{C} / \mathrm{min}$ ) and then kept for $4 \mathrm{~h}$. The yellow g- $\mathrm{C}_{3} \mathrm{~N}_{4}$ product was collected and ground into powder with an agate mortar for further use.

\subsubsection{Synthesis of $g-C_{3} N_{4} / C D s$ nanocomposite}

CDs were synthesized by the pyrolysis of citric acid and branched poly(ethylenimine) according to our previous report [31]. A typical preparation of $\mathrm{g}-\mathrm{C}_{3} \mathrm{~N}_{4} / \mathrm{CDs}$ nanocomposite was as follows: $\mathrm{g}-\mathrm{C}_{3} \mathrm{~N}_{4}(0.2 \mathrm{~g})$ and a certain volume of $\mathrm{CDs}$ aqueous solution $\left(1 \mathrm{mg} \mathrm{mL}{ }^{-1}\right.$ ) were mixed and vigorously stirred for $24 \mathrm{~h}$, followed by vaporizing the solvent at $100^{\circ} \mathrm{C}$ in an electric thermostatic drying oven. The as-obtained powder was calcined at $300^{\circ} \mathrm{C}$ for $1 \mathrm{~h}$ at ambient conditions. Following the same procedure, different mass ratios of g- $\mathrm{C}_{3} \mathrm{~N}_{4} / \mathrm{CDs}$ nanocomposites with $0.1 \mathrm{wt} \%, 0.2 \mathrm{wt} \%, 0.5 \mathrm{wt} \%$ and $1 \mathrm{wt} \% \mathrm{CDs}$, respectively, were synthesized.

\subsection{Characterization}

The morphology of the synthesized photocatalysts was examined by transmission electron microscopy (TEM) using a JEOL $2100 \mathrm{~F}$ instrument (Tokyo, Japan) operated at an accelerating voltage of $200 \mathrm{kV}$.X-ray photoelectron spectroscopy (XPS) data were obtained on a Thermo VG ESCALAB 250 spectrometer (East Grinsted, UK) with $\mathrm{Al} \mathrm{K \alpha}$ radiation at $1486.6 \mathrm{eV}$. Fourier transform infrared (FTIR) spectra were recorded on a JASCO 6100 spectrophotometer (Japan). UV-vis diffuse reflectance measurements were performed on a Varian Cary 5000 spectrometer (Palo Alto, CA, USA). Fluorescence spectra were obtained on a Horiba Fluoromax-4spectrofluorimeter (Edison, NJ, USA). The total organic carbon (TOC) was measured using a multi N/C 3000 analyzer (Analytik Jena AG, Germany). Electron spin resonance (ESR) signal of radicals spin-trapped by DMPO was recorded on a Bruker ER073 spectrometer (Karlsruhe, Germany) during visible light irradiation of the suspension ( $0.05 \mathrm{mg} \mathrm{mL}^{-1}$ photocatalyst, $100 \mathrm{mM} \mathrm{DMPO}$ ). The settings for ESR measurements were as follows: center field $3503.95 \mathrm{G}$, microwave frequency $9.84 \mathrm{GHz}$, and power $20 \mathrm{~mW}$. Photoelectrochemical measurements were performed in a three-electrode quartz cell on a CHI 630B electrochemical workstation (Shanghai, China). A Pt plate and $\mathrm{Ag} / \mathrm{AgCl}$ electrode were used as the counter electrode and reference electrode, respectively. The working electrodes were prepared by spreading a slurry of the as-prepared photocatalyst onto the fluorine-doped tin oxide (FTO) glass. Photocurrent-time curves were measured in $0.1 \mathrm{M} \mathrm{Na}_{2} \mathrm{SO}_{4}$ electrolyte. Electrochemical impedance spectra (EIS) were measured in $0.1 \mathrm{M} \mathrm{KCl}$ solution containing $2.5 \mathrm{mM} \mathrm{K}_{3}\left[\mathrm{Fe}(\mathrm{CN})_{6}\right] / \mathrm{K}_{4}\left[\mathrm{Fe}(\mathrm{CN})_{6}\right](1: 1)$ with a sinusoidal ac perturbation of $5 \mathrm{mV}$ over a frequency range of $1 \mathrm{MHz}$ to $100 \mathrm{mHz}$.

\subsection{Photocatalytic performance evaluation}

Photodegradation of a phenol solution $\left(10 \mathrm{mg} \mathrm{L}^{-1}\right)$ was performed to evaluate the photocatalytic performance of the synthesized catalysts, which was carried out in a top-window Pyrex cell with the temperature maintained at $20^{\circ} \mathrm{C}$ by a circulating water system. The catalyst $(50 \mathrm{mg}$ ) was added into the phenol solution $(50 \mathrm{~mL})$. Prior to irradiation, the suspension was magnetically stirred in the dark for 30 min to ensure phenol adsorption/desorption equilibrium. Then, the suspension was irradiated by a $300 \mathrm{~W}$ Xe lamp with a cut off filter $(<400 \mathrm{~nm})$ and an irradiation intensity of $100 \mathrm{~mW} \mathrm{~cm}^{-2}$. At given time intervals, aliquots of the irradiated suspension were collected, centrifuged and analyzed on an Aligent 1260 high-performance liquid chromatography (HPLC) (Palo Alto, CA, USA) with a Poroshell 120 EC-C18 column. 
The detection wavelength was at $280 \mathrm{~nm}$. The mobile phase was a mixture of methanol and water with a volume ratio of 55:45 and flow rate of $0.3 \mathrm{~mL} \mathrm{~min}^{-1}$.

\section{Results and discussion}

\subsection{Structural characterization of $g-C_{3} N_{4} / C D s$ composites}

TEM images showed that the as-prepared CDs were monodispersed with an average diameter of $3.6 \mathrm{~nm}$ (Fig. S1). The light-brown CDs solution displayed a broad optical absorption below $500 \mathrm{~nm}$ with a peak at $355 \mathrm{~nm}$. The photoluminescence emission of CDs exhibited an excitation wavelength dependent behavior due to the existence of different emissive states of CDs (Fig. S2) [32]. The excellent dispersibility of the CDs in water originated from the numerous oxygen- functional groups on their surface. As observed from Fig. 1, the pristine g- $\mathrm{C}_{3} \mathrm{~N}_{4}$ displayed a typical layered structure. For the $g-C_{3} N_{4} / C D s$ composite sample, CDs adhered to the g- $\mathrm{C}_{3} \mathrm{~N}_{4}$ surface, which may arise from $\pi-\pi$ stacking interactions $[16,17]$.

The interaction between the $\mathrm{CDs}$ and $\mathrm{g}-\mathrm{C}_{3} \mathrm{~N}_{4}$ was first investigated by FTIR spectra. As shown in Fig. S3, the band at $810 \mathrm{~cm}^{-1}$ could be attributed to the breathing mode of triazine units [33]. The bands in the $1200-1600 \mathrm{~cm}^{-1}$ region were corresponding to the stretching vibration of the $\mathrm{CN}$ heterocycle [34]. Notably, these bands in the $\mathrm{g}-\mathrm{C}_{3} \mathrm{~N}_{4} / \mathrm{CDs}$ composite depicted slight red-shifts as compared to those in the pristine g- $\mathrm{C}_{3} \mathrm{~N}_{4}$, e. g., $1249 \rightarrow 1237 \mathrm{~cm}^{-1}, 1328 \rightarrow 1321 \mathrm{~cm}^{-1}, 1415 \rightarrow 1406 \mathrm{~cm}^{-1}$ and $1570 \rightarrow 1568 \mathrm{~cm}^{-1}$, suggesting the bond strength of $\mathrm{C}-\mathrm{N}$ was weakened due to the strong interaction between the CDs and g- $\mathrm{C}_{3} \mathrm{~N}_{4}$ in the composites $[33,34]$. XPS spectra were further performed to comprehend the interactions (Fig. 2). The $\mathrm{N} 1 \mathrm{~s}$ spectra of both g- $\mathrm{C}_{3} \mathrm{~N}_{4}$ and $\mathrm{g}-\mathrm{C}_{3} \mathrm{~N}_{4} / \mathrm{CDs}$ composite presented the typical tertiary $\mathrm{N}-(\mathrm{C})_{3}$ groups $(399.8 \mathrm{eV})$ and triazine rings (398.5 eV) [35]. Interestingly, a new shoulder peak at $397.6 \mathrm{eV}$ was obviously observed in $\mathrm{g}-\mathrm{C}_{3} \mathrm{~N}_{4} / \mathrm{CDs}$ composite, which might be caused by the significant interaction between the $\mathrm{CDs}$ and the $\mathrm{N}$ atoms in the $\mathrm{g}-\mathrm{C}_{3} \mathrm{~N}_{4}[23]$. The $C$ 1s spectra of the $\mathrm{g}-\mathrm{C}_{3} \mathrm{~N}_{4}$ could be deconvoluted into two species: $\mathrm{sp}^{2}$-bonded $\mathrm{C}$ atoms $\mathrm{N}-\mathrm{C}=\mathrm{N}(288.1 \mathrm{eV})$ and $\mathrm{C}=\mathrm{C}(284.6 \mathrm{eV})$. The two new peaks in $\mathrm{g}_{-} \mathrm{C}_{3} \mathrm{~N}_{4} / \mathrm{CDs}$ composite was attributed to $\mathrm{C}-\mathrm{OH}$ (285.7) and $\mathrm{COOH}(289.1 \mathrm{eV})$ species in CDs [31]. These results suggest the $\pi-\pi$ stacking interaction between $g-C_{3} N_{4}$ and CDs should be responsible for the assembly of $g-\mathrm{C}_{3} \mathrm{~N}_{4} / \mathrm{CDs}$ composites. Such noncovalent interactions between the two components prevent the formation of defects at the junction interface and thus give rise to a high-quality contact interface.

The optical absorption properties of the resultant $\mathrm{g}-\mathrm{C}_{3} \mathrm{~N}_{4} / \mathrm{CDs}$ composites were examined with UV-vis diffuse reflectance spectroscopy (Fig. 3a). Pristine g- $\mathrm{C}_{3} \mathrm{~N}_{4}$ exhibited an intrinsic absorption edge at $460 \mathrm{~nm}$ with a calculated band gap of $2.7 \mathrm{eV}$ according to the Kubelka-Munk function [36]. After the introduction of CDs, the absorption edge of $\mathrm{g}-\mathrm{C}_{3} \mathrm{~N}_{4}$ did not shift, which suggested that the $\mathrm{CDs}$ were probably anchored onto the surface of $\mathrm{g}-\mathrm{C}_{3} \mathrm{~N}_{4}$ and therefore did not change its bulk optical properties. The visible light harvesting capability of the $\mathrm{g}-\mathrm{C}_{3} \mathrm{~N}_{4} / \mathrm{CDs}$ composites increased with the $\mathrm{CDs}$ content due to the intrinsic optical absorbance of the CDs. Indeed, CDs can absorb visible light with longer wavelength $(>550 \mathrm{~nm})$ and then emit photoluminescence at a shorter wavelength $(400-500 \mathrm{~nm})$ due to the upconverted photoluminescence property (Fig. 3b), which can be attributed to a multiphoton active process [26,37]. These results suggest that CDs can serve as a light harvesting component for $\mathrm{g}-\mathrm{C}_{3} \mathrm{~N}_{4}$ to improve visible light utilization, which should enhance the photocatalytic performance of the g- $\mathrm{C}_{3} \mathrm{~N}_{4} /$ CDs composites under sunlight.

\subsection{Photocatalytic performance of $g-C_{3} N_{4} / C D$ s composites}

The photocatalytic performance of the synthesized catalysts was evaluated by phenol degradation experiments, which is a typical intermediate in the degradation of aromatic hydrocarbons and is difficult to degrade using conventional degradation technologies. As shown in Fig. 4a, phenol was stable under visible light irradiation in the absence of a photocatalyst. After the addition of g- $\mathrm{C}_{3} \mathrm{~N}_{4}$ or $\mathrm{g}-\mathrm{C}_{3} \mathrm{~N}_{4} / \mathrm{CDs}$ composites, phenol degradation occurred upon light irradiation. Greatly enhanced phenol degradation was observed upon the introduction of CDs onto g- $\mathrm{C}_{3} \mathrm{~N}_{4}$. For the composite containing $0.5 \mathrm{wt} \% \mathrm{CDs}$, the phenol solution was completely degraded within $200 \mathrm{~min}$, whereas only about $50 \%$ phenol was decomposed over the pristine $\mathrm{g}-\mathrm{C}_{3} \mathrm{~N}_{4}$ sample during the same period. To quantitatively analyze the catalytic efficiency, the phenol degradation rates were extracted by assuming pseudo-first-order kinetics (Fig. 4b). All the g- $\mathrm{C}_{3} \mathrm{~N}_{4} / \mathrm{CDs}$ catalysts exhibited 1.9 to 3.7 times higher rate constants than the pristine $\mathrm{g}-\mathrm{C}_{3} \mathrm{~N}_{4}$, indicating that CDs indeed boosted the photocatalytic activity of g- $\mathrm{C}_{3} \mathrm{~N}_{4}$.

The wavelength-dependent phenol degradation experiments were further conducted to investigate the effect of the increased absorption induced by CDs (as shown in Fig. 3a) on the photocatalytic efficiency. Fig. S4 showed the phenol degradation efficiency over the g- $\mathrm{C}_{3} \mathrm{~N}_{4} / \mathrm{CDs}$ catalysts under different light wavelength. For light with $450 \pm 20 \mathrm{~nm}$ wavelength, an increasing photocatalytic activity toward phenol degradation was observed with increased CDs content $(<0.5 \mathrm{wt} \%$ ), which was similar to that under the whole visible light region. For light with $550 \pm 20 \mathrm{~nm}$ wavelength, although $\mathrm{g}-\mathrm{C}_{3} \mathrm{~N}_{4}$ only absorb $<460 \mathrm{~nm}$ light, phenol degradation still occurred in the presence of $\mathrm{g}-\mathrm{C}_{3} \mathrm{~N}_{4} / \mathrm{CDs}$ catalysts, which should be attributed to the CDs upconversion [22]. These results suggest that CDs would increase light harvesting capability of the g- $\mathrm{C}_{3} \mathrm{~N}_{4} / \mathrm{CDs}$ composites and then promote the phenol degradation. However, the photocatalytic activity of $\mathrm{g}-\mathrm{C}_{3} \mathrm{~N}_{4} / \mathrm{CDs}$ composites dramatically decreased with CDs contents exceeded $0.5 \mathrm{wt} \%$. This decrease is likely related to the "shielding effect" of the carbon material, which reduces light absorption and masks the active sites of the catalyst $[17,38]$. The highest photocatalytic activity was obtained for the composite with $0.5 \mathrm{wt} \% \mathrm{CDs}$, which was therefore used in subsequent experiments and labeled as $\mathrm{g}-\mathrm{C}_{3} \mathrm{~N}_{4} / \mathrm{CDs}$.

The main intermediate products during the phenol photodegradation were displayed in Fig. 5a. Three typical intermediates including catechol, hydroquinone and $p$-benzoquinone were clearly observed. The concentration of these intermediates reached a maximum and then gradually declined with the irradiation time due to the ring cleavage process. The formed organic acids were further degraded to $\mathrm{CO}_{2}$ and $\mathrm{H}_{2} \mathrm{O}$. This is consistent with the previous studies on phenol degradation by the $\bullet \mathrm{OH}$ attack $[39,40]$. The proposed phenol photodegradation pathways were illustrated in Fig. S5. To further demonstrate the mineralization degree of phenol during photodegradation process, the evolution of TOC during light irradiation was investigated (Fig. 5b). Similarly, about $87 \%$ of phenol was mineralized to $\mathrm{CO}_{2}$ within $200 \mathrm{~min}$ in the presence of g- $\mathrm{C}_{3} \mathrm{~N}_{4} / \mathrm{CDs}$ composites. For comparison, the TOC value was only reduced by $43 \%$ for the pristine $\mathrm{g}-\mathrm{C}_{3} \mathrm{~N}_{4}$ during the same period. This indicates the $g-\mathrm{C}_{3} \mathrm{~N}_{4} / \mathrm{CDs}$ composites possessed much higher mineralization efficiency for phenol photodegradation than $\mathrm{C}_{3} \mathrm{~N}_{4}$ catalyst.

Considering the importance of photocatalyst stability in practical applications, the reusability of the $\mathrm{g}-\mathrm{C}_{3} \mathrm{~N}_{4} / \mathrm{CDs}$ composites for phenol degradation was evaluated (Fig. 6). Over five consecutive cycles, no obvious deactivation of the photocatalyst was observed. TEM analysis indicated that the distribution and density of CDs on the $\mathrm{g}-\mathrm{C}_{3} \mathrm{~N}_{4}$ surface were indistinguishable from those of the unused sample after photocatalytic cycle (Fig. S6). These results clearly 

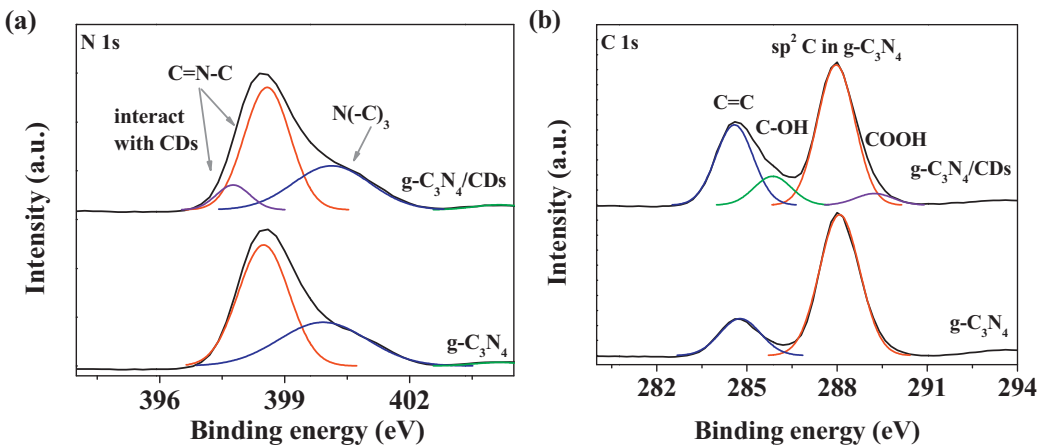

Fig. 2. (a) $\mathrm{N} 1 \mathrm{~s}$ and (b) $\mathrm{C} 1 \mathrm{~s}$ XPS spectra of $\mathrm{g}-\mathrm{C}_{3} \mathrm{~N}_{4}$ and $\mathrm{g}-\mathrm{C}_{3} \mathrm{~N}_{4} / \mathrm{CDs}(0.5 \mathrm{wt} \%)$ composite.

(a)

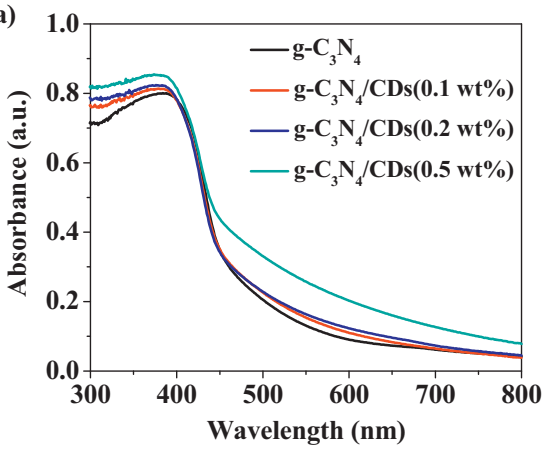

(b)

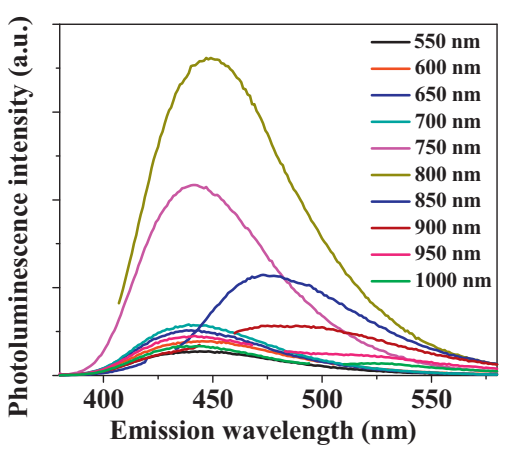

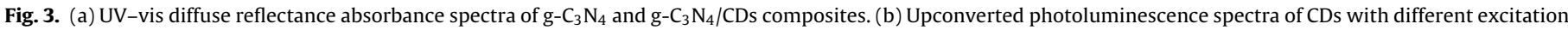
wavelength.

(a)

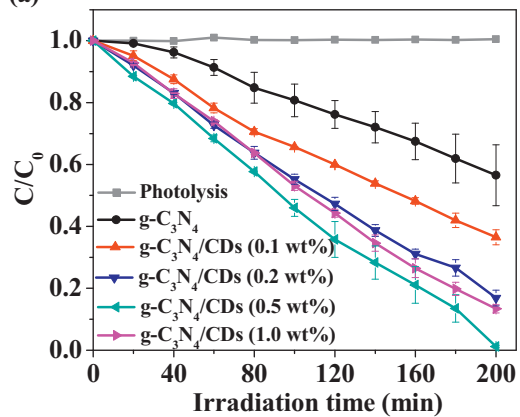

(b)

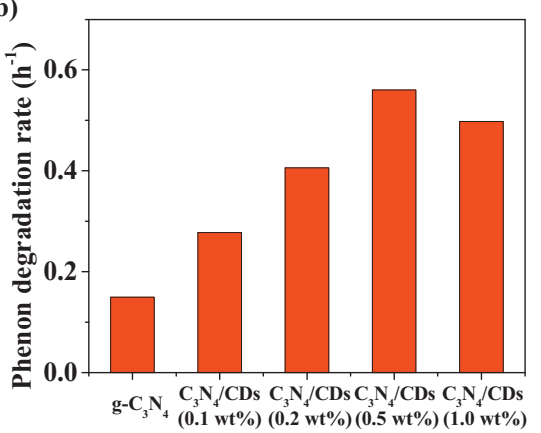

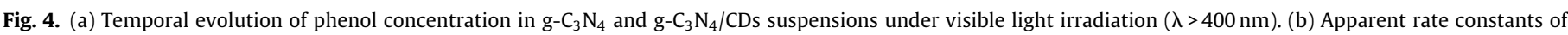
phenol degradation over different photocatalysts.
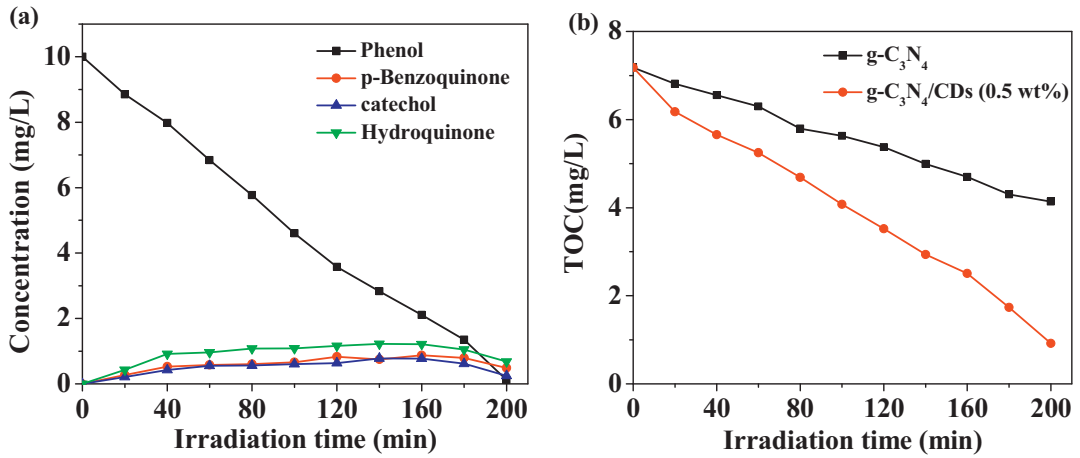

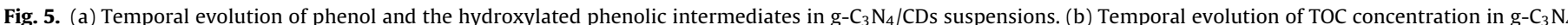
and $g-C_{3} N_{4} / C D$ s suspensions under visible light irradiation $(\lambda>400 \mathrm{~nm})$. 


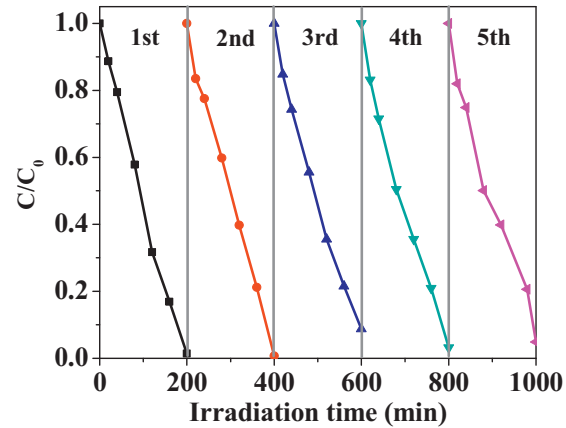

Fig. 6. Recycling performance ofg- $\mathrm{C}_{3} \mathrm{~N}_{4} / \mathrm{CDs}$ composite towards phenol degradation under visible light irradiation $(\lambda>400 \mathrm{~nm})$.

indicate the high- stability of the $\mathrm{g}-\mathrm{C}_{3} \mathrm{~N}_{4} / \mathrm{CD}$ composite during the photocatalytic reaction.

\subsection{Photocatalytic mechanism for $\mathrm{g}-\mathrm{C}_{3} \mathrm{~N}_{4} / \mathrm{CD}$ s composites}

To elucidate the phenol degradation mechanism by the g$\mathrm{C}_{3} \mathrm{~N}_{4} / \mathrm{CDs}$ composite, the generation of reactive oxygen species (ROS) over the $\mathrm{g}-\mathrm{C}_{3} \mathrm{~N}_{4} / \mathrm{CDs}$ composite under visible light irradiation was probed by a DMPO spin-trapping ESR technique. As shown in Fig. 7, no ESR signal was observed in the dark. Upon visible light irradiation, a four-line ESR signal with an intensity ratio of $1: 1: 1: 1$ was clearly observed, which is characteristic of DMPO- ${ }^{\bullet} \mathrm{O}_{2}-$ adduct. The $\bullet \mathrm{OH}$ radical was also captured to form DMPO- $\bullet$ OH adduct with a characteristic $1: 2: 2: 1$ quadruplet and spacing of $15 \mathrm{G}$ in the magnetic field [41]. Since the photogenerated holes in the valance band of $\mathrm{g}-\mathrm{C}_{3} \mathrm{~N}_{4}\left(E_{\mathrm{VB}}=+1.40 \mathrm{~V}\right.$, vs. NHE) are incapable of oxidizing hydroxyl groups into ${ }^{\bullet} \mathrm{OH}$ radicals $\left(E\left({ }^{\bullet} \mathrm{OH} / \mathrm{OH}^{-}\right)=+1.99 \mathrm{~V}\right.$, vs. NHE) due to the more negative valance band potential [42], it is believed that the observed ${ }^{\circ} \mathrm{OH}$ radicals were generated from the $\cdot \mathrm{O}_{2}{ }^{-}$radicals by photochemical reaction. Time-dependent ESR signals were also measured under the same conditions, where the intensity of the ESR signal could imply the concentration of ROS generated in each catalyst suspension. The intensity of radical signals gradually enhanced in both catalysts as the irradiation time increased, indicating the important role of ${ }^{\bullet} \mathrm{O}_{2}{ }^{-}$and ${ }^{\bullet} \mathrm{OH}$ radicals in degrading phenol. A notable observation came from the higher formation rates of ${ }^{\bullet} \mathrm{O}_{2}{ }^{-}$and ${ }^{\bullet} \mathrm{OH}$ radicals in $\mathrm{g}-\mathrm{C}_{3} \mathrm{~N}_{4} / \mathrm{CDs}$ systems than in the $\mathrm{g}-\mathrm{C}_{3} \mathrm{~N}_{4}$ one. This trend is consistent with the observed phenol degradation rate, and demonstrates that more ROS could attack phenol molecules in the g- $\mathrm{C}_{3} \mathrm{~N}_{4} / \mathrm{CDs}$ system and subsequently promote their degradation than in the $\mathrm{g}-\mathrm{C}_{3} \mathrm{~N}_{4}$ system.

In addition to the above ROS generation analysis, the transient photocurrent responses of $\mathrm{g}-\mathrm{C}_{3} \mathrm{~N}_{4}$ and g- $\mathrm{C}_{3} \mathrm{~N}_{4} / \mathrm{CDs}$ composite were measured to examine the charge generation and recombination behaviors in these photocatalyst systems. The reproducible photocurrent responses during the "on-off" irradiation cycles in Fig. 8a confirmed the good stability of the $\mathrm{g}_{-} \mathrm{C}_{3} \mathrm{~N}_{4}$ and $\mathrm{g}-\mathrm{C}_{3} \mathrm{~N}_{4} / \mathrm{CDs}$ photoelectrodes. Notably, the introduction of $\mathrm{CDs}$ resulted in about two-fold enhancement in the photocurrent density compared to that of the pristine $\mathrm{g}-\mathrm{C}_{3} \mathrm{~N}_{4}$ electrode. Because the photocurrent arises from the transport of photogenerated electrons to the back contact and the simultaneous capture of photogenerated holes by hole scavengers in the electrolyte, the enhanced photocurrent (a)

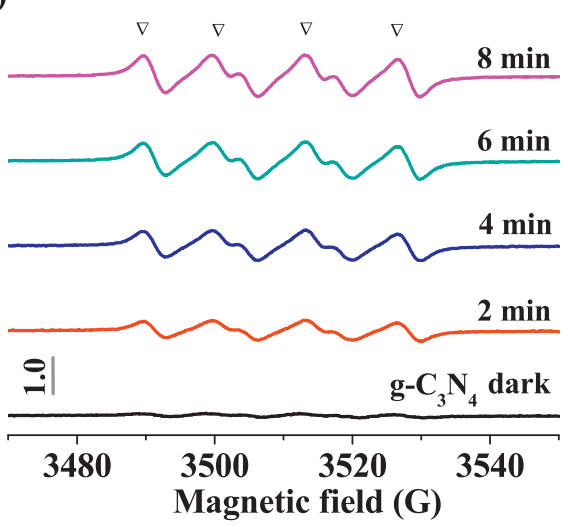

(b)

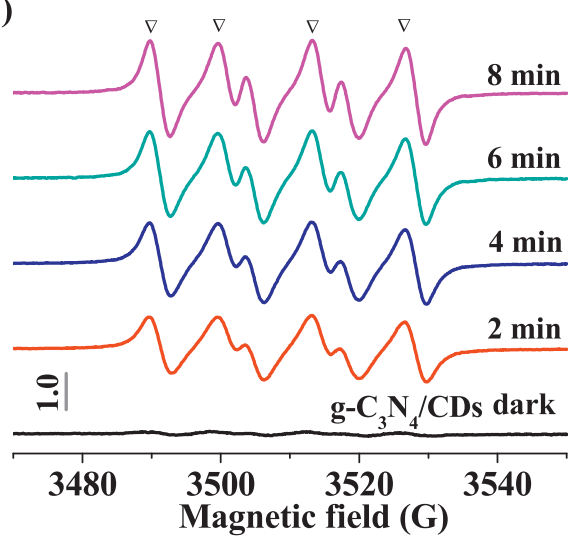

(c)

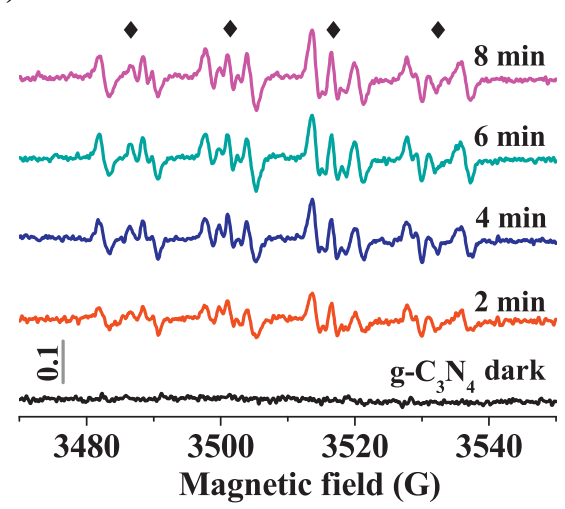

(d)

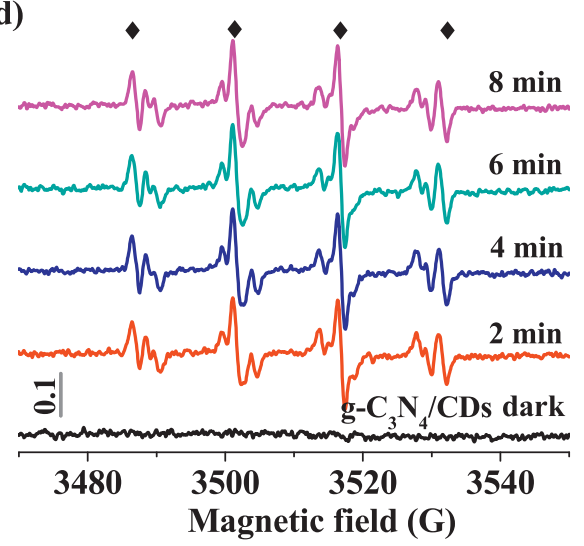

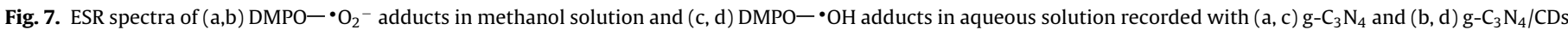

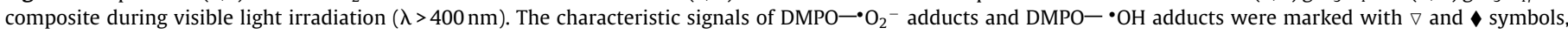
respectively. 
(a)

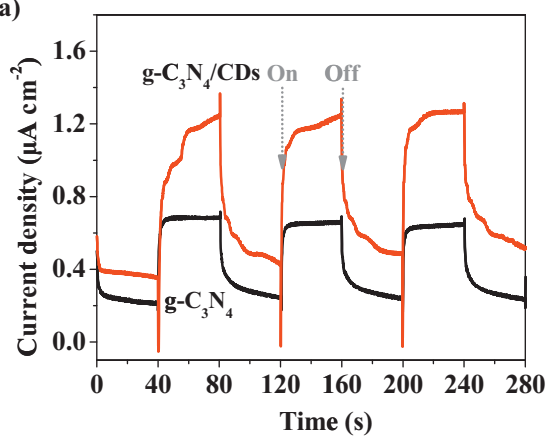

(b)

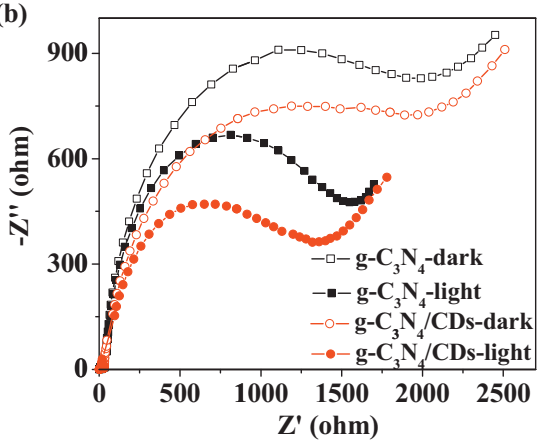

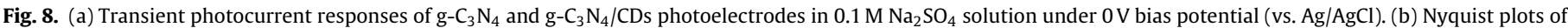
g- $\mathrm{C}_{3} \mathrm{~N}_{4}$ and g- $\mathrm{C}_{3} \mathrm{~N}_{4} / \mathrm{CDs}$ photoelectrodes in $0.1 \mathrm{M} \mathrm{Na}_{2} \mathrm{SO}_{4}$ solution in the dark and under visible light irradiation $(\lambda>400 \mathrm{~nm})$.

response of the $\mathrm{g}-\mathrm{C}_{3} \mathrm{~N}_{4} / \mathrm{CDs}$ electrode compared with the $\mathrm{g}-\mathrm{C}_{3} \mathrm{~N}_{4}$ electrode demonstrates that $\mathrm{CDs}$ promoted the efficient generation and separation of photogenerated electron-hole pairs, which are favorable for ROS generation and thus photocatalytic activity.

Another interesting observation came from the relatively slow photocurrent response of the $\mathrm{g}-\mathrm{C}_{3} \mathrm{~N}_{4} / \mathrm{CDs}$ sample during the "onoff" irradiation cycles. The delayed response of the composite electrode suggested that the CDs could capture and store the photoexcited electrons. A similar phenomenon has been observed in the carbon and noble-metal based composites [43,44]. Upon light irradiation, CDs could serve as electron reservoirs to store the photogenerated electrons, so only a portion of the photoelectrons are transported to the back contact electrode until the equilibrium state is reached. Thus, a gradually rising photocurrent response occurs. Similarly, the slow release of photoelectrons from the CDs could cause the slow response of the photocurrent delay curve when the irradiation is switched off. These results suggest that the photocarrier recombination is slower in the $\mathrm{g}-\mathrm{C}_{3} \mathrm{~N}_{4} / \mathrm{CDs}$ composite than in g- $\mathrm{C}_{3} \mathrm{~N}_{4}$, which partly explains the markedly enhanced photocatalytic activity of the composites.

To validate the improved charge transfer behaviors of the g$\mathrm{C}_{3} \mathrm{~N}_{4} / \mathrm{CDs}$, the EIS Nynquist plots of the two photoelectrodes in the dark and under illumination conditions were presented in Fig. 8b. The semicircle part at the high frequency region is associated with the charge-transfer process at the photoelectrode interface and a smaller radius implies more efficient charge transfer process [45]. Compared with the plot obtained in the dark, a much smaller radius was obtained under irradiation for both electrodes, consistent with the increased electron conductivity of the electrode under light. The semicircle in the Nyquist plot of the $\mathrm{g}-\mathrm{C}_{3} \mathrm{~N}_{4} / \mathrm{CDs}$ electrode exhibited a smaller radius than that of the $\mathrm{g}_{-} \mathrm{C}_{3} \mathrm{~N}_{4}$ electrode, implying that interfacial charge transfer occurred more rapidly at the heterojunction interface of $g-\mathrm{C}_{3} \mathrm{~N}_{4} / \mathrm{CDs}$ than in $\mathrm{g}-\mathrm{C}_{3} \mathrm{~N}_{4}$ and thus promoted efficient separation of the photogenerated electron-hole pairs.

Based on the above photocatalytic and photoelectrochemical analysis, a tentative mechanism for the enhanced photocatalytic performance of the $\mathrm{g}-\mathrm{C}_{3} \mathrm{~N}_{4} / \mathrm{CDs}$ composite was proposed, which is illustrated in Fig. 9. Under visible light irradiation, g- $\mathrm{C}_{3} \mathrm{~N}_{4}$ could absorb light with wavelength $<470 \mathrm{~nm}$. Simultaneously, light of wavelength $>550 \mathrm{~nm}$ could be converted to $<470 \mathrm{~nm}$ light by the incorporated $\mathrm{CDs}$, which subsequently excites $\mathrm{g}-\mathrm{C}_{3} \mathrm{~N}_{4}$ to generate electron-hole pairs [26] Importantly, the relative band alignment of $g-\mathrm{C}_{3} \mathrm{~N}_{4}$ and $\mathrm{CDs}$ provides the feasibility of the migration of photoexcited electrons from $\mathrm{g}-\mathrm{C}_{3} \mathrm{~N}_{4}$ to $\mathrm{CDs}$. These processes greatly inhibit the recombination of photogenerated charge carriers. Thus, the $\mathrm{g}-\mathrm{C}_{3} \mathrm{~N}_{4} / \mathrm{CDs}$ composite could not only promote charge generation by extending the absorption region toward sunlight spectra, but also facilitate charge separation and transport at the junction interface, which subsequently enhances the charge carrier genera-

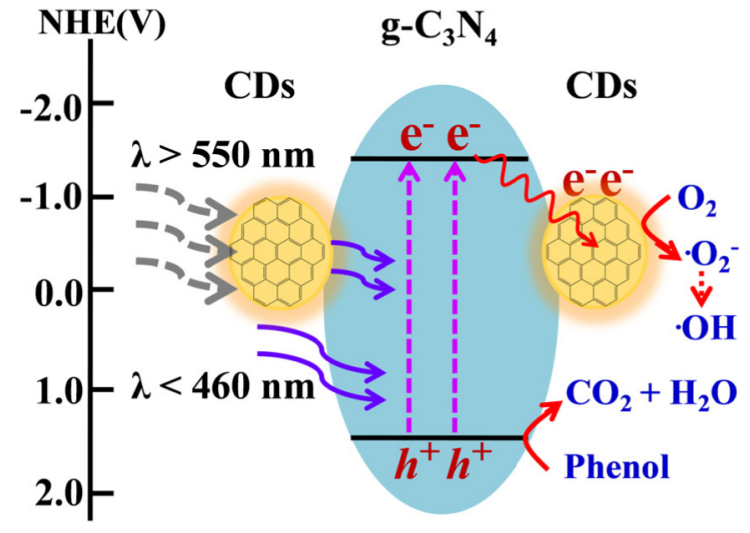

Fig. 9. Schematic illustration of the possible photocatalytic processes in the g$\mathrm{C}_{3} \mathrm{~N}_{4} / \mathrm{CDs}$ composite under visible light.

tion and facilitate their reaction with the adsorbed species (such as $\mathrm{O}_{2}$ and $\mathrm{OH}^{-}$) to yield $\mathrm{ROS}\left(\right.$ e.g., $\left.{ }^{\bullet} \mathrm{O}_{2}^{-}, \cdot \bullet \mathrm{OH}\right)$, accelerating the phenol degradation.

\section{Conclusion}

In summary, we developed a facile method to fabricate a metalfree $\mathrm{g}-\mathrm{C}_{3} \mathrm{~N}_{4} / \mathrm{CDs}$ photocatalyst to degrade organic contaminants. The similar $\pi-\pi$ conjugated structure of the $g-C_{3} N_{4}$ and CDs components ensured the formation of a high-quality contact interface in the $\mathrm{g}-\mathrm{C}_{3} \mathrm{~N}_{4} / \mathrm{CDs}$ composite. Because of the extended visible light absorption range provided by the upconverted photoluminescence character of CDs and efficient charge separation arising from the energy alignment structure, the $\mathrm{g}-\mathrm{C}_{3} \mathrm{~N}_{4} / \mathrm{CDs}$ composite exhibited up to 3.7-fold enhancement in phenol degradation rate constant than that of the pristine $\mathrm{g}-\mathrm{C}_{3} \mathrm{~N}_{4}$ under visible light irradiation. This work will encourage new developments in metal-free photocatalysts and promote their practical application in environmental remediation.

\section{Acknowledgments}

This work was supported by the National Basic Research Program of China (2011CB936001) and National Natural Science Foundation of China (21321004, 21207146, 21177138, 21477146 and 21377142). 


\section{Appendix A. Supplementary data}

Supplementary data associated with this article can be found, in the online version, at http://dx.doi.org/10.1016/j.apcatb.2015. 06.056

\section{References}

[1] Z. Zou, J. Ye, K. Sayama, H. Arakawa, Nature 414 (2001) 625-627.

[2] A. Kudo, Y. Miseki, Chem. Soc. Rev. 38 (2009) 253-278.

[3] M.R. Hoffmann, S.T. Martin, W. Choi, D.W. Bahnemann, Chem. Rev. 95 (1995) 69-96.

[4] W.Y. Teoh, J.A. Scott, R. Amal, J. Phys. Chem. Lett. 3 (2012) 629-639.

[5] W.J. Jo, J.W. Jang, K.J. Kong, H.J. Kang, J.Y. Kim, H. Jun, K.P.S. Parmar, J.S. Lee, Angew. Chem. Int. Ed. 51 (2012) 3147-3151.

[6] F.X. Zhang, A. Yamakata, K. Maeda, Y. Moriya, T. Takata, J. Kubota, K. Teshima S. Oishi, K. Domen, J. Am. Chem. Soc. 134 (2012) 8348-8351.

[7] X. Zong, G. Wu, H. Yan, G. Ma, J. Shi, F. Wen, L. Wang, C. Li, J. Phys. Chem. C 114 (2010) 1963-1968.

[8] H. Tong, S.X. Ouyang, Y.P. Bi, M. Oshikiri, N. Umezawa, M. Oshikiri, J.H. Ye, Adv. Mater. 24 (2012) 229-251.

[9] X.C. Wang, K. Maeda, A. Thomas, K. Takanabe, G. Xin, J.M. Carlsson, K. Domen, M.A. Antonietti, Nat. Mater. 8 (2009) 76-80.

[10] S. Chao, J. Yu, J. Phys. Chem. Lett. 5 (2014) 2101-2107.

[11] Y.J. Cui, Z.X. Ding, X.Z. Fu, X.C. Wang, Angew. Chem. Int. Ed. 51 (2012) 11814-11818.

[12] Y. Wang, Y. Shi, J. Lin, Y. Zhu, Energy Environ. Sci. 4 (2011) 2922-2929.

[13] Z. Lin, X. Wang, ChenSunChem 7 (2014) 1547-1550.

[14] Y. Zhen, L. Lin, X. Ye, F. Guo, X. Wang, Angew. Chem. Int. Ed. 53 (2014) 11926-11930.

[15] S. Samanta, S. Martha, K. Parida, ChemCatChem 6 (2014) 1453-1462.

[16] S.K. Bhunia, N.R. Jana, ACS Appl. Mater. Interfaces 6 (2014) 20085-20092.

[17] Y. Li, H. Zhang, P. Liu, D. Wang, Y. Li, H. Zhao, Small 9 (2013) 3336-3344.

[18] R.C. Pawar, S. Kang, S.H. Ahn, C.S. Lee, RSC Adv. 5 (2015) 24281-24292.

[19] J. Chen, S. Shen, P. Guo, M. Wang, B. Wu, X. Wang, L. Guo, Appl. Catal. B 152-153 (2014) 335-341.

[20] K. Chang, Z. Mei, T. Wang, Q. Kang, S. Ouyang, J. Ye, ACS Nano 8 (2014) 7078-7087.

[21] X. Wang, S. Blechert, M. Antonietti, ACS Catal. 2 (2012) 1596-1606.

[22] J. Zhang, M. Zhang, R.-Q. Sun, X. Wang, Angew. Chem. Int. Ed. 51 (2012) 10145-110149.
[23] J. Zhang, M. Zhang, L. Lin, X. Wang, Angew. Chem. Int. Ed. 54 (2015) 6297-6301.

[24] Y.P. Sun, B. Zhou, Y. Lin, W. Wang, K.A.S. Fernando, P. Pathak, M.J. Meziani, B.A. Harruff, X. Wang, H. Wang, P.G. Luo, H. Yang, M.E. Kose, B. Chen, L.M. Veca, S.Y. Xie, J. Am. Chem. Soc. 128 (2006) 7756-7757.

[25] M.J. Krysmann, A. Kelarakis, P. Dallas, E.P. Giannelis, J. Am. Chem. Soc. 134 (2012) 747-750.

[26] H.T. Li, X.D. He, Z.H. Kang, H. Huang, Y. Liu, J.L. Liu, S.Y. Lian, C.H.A. Tsang, X.B. Yang, S.T. Lee, Angew. Chem. Int. Ed. 49 (2010) 4430-4434.

[27] C. Xie, B. Nie, L. Zeng, F.-X. Liang, M.-Z. Wang, L. Luo, M. Feng, Y. Yu, C.-Y. Wu, Y. Wu, S.-H. Yu, ACS Nano 8 (2014) 4015-4022.

[28] H.C. Zhang, H. Huang, H. Ming, H.T. Li, L.L. Zhang, Y. Liu, Z.H. Kang, J. Mater. Chem. 22 (2012) 10501-10506.

[29] H. Wang, Z. Wei, H. Matsui, S. Zhou, J. Mater. Chem. A 2 (2014) 15740-15745.

[30] X.-H. Li, J. Zhang, X. Chen, A. Fischer, A. Thomas, M. Antonietti, X. Wang, Chem. Mater. 23 (2011) 4344-4348.

[31] L. Zhao, F. Geng, F. Di, L.-H. Guo, B. Wan, Y. Yang, H. Zhang, G. Sun, RSC Adv. 4 (2014) 45768-45771.

[32] S.N. Baker, G.A. Baker, Angew. Chem. Int. Ed. 49 (2010) 6726-6744.

[33] T.Y. Ma, S. Dai, M. Jaroniec, S.Z. Qiao, Angew. Chem. Int. Ed. 53 (2014) 7281-7285.

[34] W.-J. Ong, L.-L. Tan, S.-P. Chai, S.-T. Yong, Chem. Commun. 51 (2015) 858-861.

[35] S. Yang, X. Feng, X. Wang, K. Müllen, Angew. Chem. Int. Ed. 50 (2011) 5339-5343.

[36] A. Tsuge, Y. Uwamino, T. Ishizuka, K. Suzuki, Appl. Spectrosc. 45 (1991) $1377-1380$

[37] L. Cao, X. Wang, J.M. Meziani, F. Lu, H. Wang, P.G. Luo, Y. Lin, B.A. Harruff, L.M. Veca, D. Murray, S.Y. Xie, Y.P. Sun, J. Am. Chem. Soc. 129 (2007) 11318-11319.

[38] H. Zhang, X. Fan, X. Quan, S. Chen, H. Yu, Environ. Sci. Technol. 45 (2011) 5731-5736.

[39] Y.J. Liu, X.Z. Jiang, Environ. Sci. Technol. 39 (2005) 8512-8517.

[40] R. Su, R. Tiruvalam, Q. He, N. Dimitratos, L. Kesavan, C. Hammond, J.A. Lopez-Sanchez, R. Bechstein, C.J. Kiely, G.J. Hutchings, F. Besenbacher, ACS Nano 6 (2012) 6284-6292.

[41] H. Wang, Y. Su, H. Zhao, H. Yu, S. Chen, Y. Zhang, X. Quan, Environ. Sci. Technol. 48 (2014) 11984-11990.

[42] H. Zhang, L.-H. Guo, L. Zhao, B. Wan, Y. Yang, J. Phys. Chem. Lett. 6 (2015) 958-963.

[43] L. Liu, T.D. Dao, R. Kodiyath, Q. Kang, H. Abe, T. Nagao, J. Ye, Adv. Funct. Mater. 24 (2014) 7754-7762.

[44] D. Jiang, W. Wang, S. Sun, L. Zhang, Y. Zheng, ACS Catal. 5 (2015) 613-621

[45] G. Li, F. Wang, Q. Jiang, X. Gao, P. Shen, Angew. Chem. Int. Ed. 49 (2010) 3653-3656. 